\title{
Depression of melting point of multidomained bismuth in aluminum based metallic glass nanocomposites
}

\author{
R. Goswami and K. Chattopadhyay ${ }^{\text {a) }}$ \\ Center for Advanced Studies, Department of Metallurgy, Indian Institute of Science, Bangalore 560012 , \\ India
}

\begin{abstract}
We report the synthesis of nanocomposites of $\mathrm{Bi}$ in an aluminum based metallic glass matrix by rapid solidification. It is shown that constrained melting and solidification of nanometer sized embedded $\mathrm{Bi}$ particles lead to the formation of symmetry related multidomained particles. The $\mathrm{Bi}$ particles exhibit a significantly large depression of bulk melting point (over $100 \mathrm{~K}$ ) requiring a free energy gain of greater than $0.7 \times 10^{8} \mathrm{~J} \mathrm{~m}^{-3}$. This cannot be explained by the size dependence of melting points or other pressure effects and represents an intrinsic characteristic of the multidomained particles.
\end{abstract}

Controlling the nucleation of the phase separating liquid prior to the solidification, using the rapid solidification processing techniques, can provide a promising route to manufacture a class of nanocomposites where nanoscaled particles are embedded in a crystalline matrix. ${ }^{1,2}$ Such a material can have wide application in nanotechnology including antifriction materials. A suitable addition of alloying elements offer the possibility of avoiding the solidification of the matrix and thereby, producing a composite of nanocrystalline particles embedded in a metallic glass matrix. In this letter we report synthesis of nanosized $\mathrm{Bi}$ particles in an aluminum based glassy matrix and show that the constraining influence of the glassy matrix leads to multiple domain formation in the initial single-crystal particles during cycling through melting and solidification. Following this, we report and discuss an unusual depression of the bulk melting point of these embedded Bi particles.

$\mathrm{Al}$ and $\mathrm{Si}$ are miscible in molten state and form an eutectic system with very little solubility in the solid state at room temperature. ${ }^{3}$ The addition of the Fe stabilizes the melt and promotes the formation of the metallic glass. ${ }^{4}$ The interactions of $\mathrm{Bi}$ with all these three elements are highly repulsive and are reflected in the appearance of liquid immiscibility in binary couples. ${ }^{3,5}$ The phase diagrams also indicate that the solid solubility of $\mathrm{Bi}$ with the three elements are negligible in solid state. Thus, interaction of $\mathrm{Bi}$ with $\mathrm{Al}-\mathrm{Si}-\mathrm{Fe}$ is also expected to yield liquid immiscibility and should provide opportunity for synthesizing nanometric dispersion of $\mathrm{Bi}$ in glassy $\mathrm{Al}-\mathrm{Fe}-\mathrm{Si}$ matrix. We have chosen a known glass forming composition $\mathrm{Al}_{65} \mathrm{Si}_{15} \mathrm{Fe}_{20}$ for our study.

The alloys are prepared from high purity (>99.999\%) constituent elements by induction melting and rapidly solidified using melt spinning technique. The analyzed composition in atom percent is $\mathrm{Al}_{65} \mathrm{Si}_{16.4} \mathrm{Fe}_{19.4} \mathrm{Bi}_{0.7}$. The ribbon samples were characterized by a JEOL FXII transmission electron microscope (TEM) and thermal studies were carried out under dynamic argon atmosphere using a Perkin Elmer DSC IIC differential scanning calorimeter (DSC) with a heating and cooling rate of $20 \mathrm{~K} / \mathrm{min}$.

A typical microstructure of the nanocomposite is shown

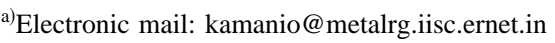

in Fig. 1(a). The electron diffraction pattern [Fig. 1(b)] confirms the existence of glassy matrix and crystalline rhombohedral $\mathrm{Bi}$. The sizes of the Bi particles vary between 5-30 $\mathrm{nm}$ with a $\log$ normal distribution. The glassy matrix is stable up to $585 \mathrm{~K}$. The decomposition process is complete at $700 \mathrm{~K}$. Electron diffraction of the quenched samples from above this temperature indicates a crystalline matrix having a tetragonal crystal structure $(a=0.612 \mathrm{~nm}$ and $c=0.943 \mathrm{~nm})$.

Most of the $\mathrm{Bi}$ particles in as solidified state was found to be single crystal. However, cycling the samples above the melting point of $\mathrm{Bi}$ (but below the crystallization point of the glass) and subsequent cooling leads to a major change in the morphology of the $\mathrm{Bi}$ nanoparticles. Most of the particles $(>80 \%)$ after third cycle show crystallographically distinct multiple domains (Fig. 2).

The results of the investigation on melting and solidification behavior of the nanometric $\mathrm{Bi}$ can be summarized as follows. The Bi melts with an onset at $523 \mathrm{~K}$ and a peak at $545 \mathrm{~K}$ in the as-cast condition. In the rapidly solidified samples, a small fraction of the $\mathrm{Bi}$ particles starts melting fairly early and over a range of temperature. These do not give any resolvable endothermic peak. However, stopping the heating cycle and cooling from a lower temperature [460 $\mathrm{K}$ for Fig. 3(a)] yield a distinct and sharp solidification peak indicating the occurrence of melting. In addition, one ob-

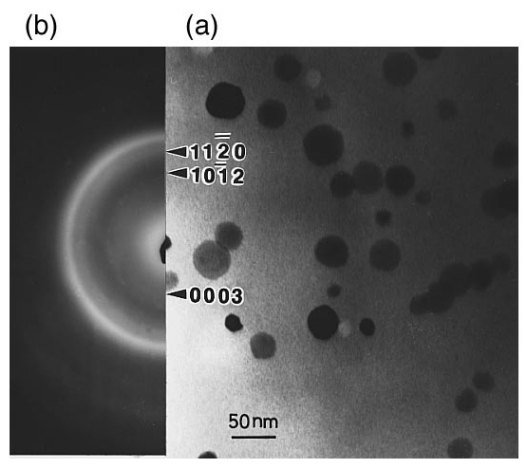

FIG. 1. (a) A bright field micrograph showing the distribution of the nanometric Bi particles in metallic glass matrix in a rapidly solidified sample of $\mathrm{Al}_{63.5} \mathrm{Si}_{16.4} \mathrm{Fe}_{19.4} \mathrm{Bi}_{0.7}$ alloy. (b) Selected area diffraction pattern from the above showing the diffuse ring due to metallic glass and the sharper rings due to Bi particles. 


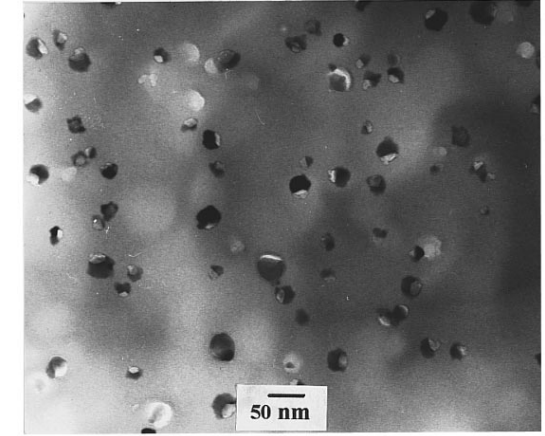

FIG. 2. A bright field micrograph showing multiple domained particles of $\mathrm{Bi}$ after heating the sample to $560 \mathrm{~K}$ and cooling to room temperature. Note the difference in contrast due to multiple domains in a single particle.

serves a broad endothermic peak with an onset at $503 \mathrm{~K}$ and a peak at $523 \mathrm{~K}$ [Fig. 3(b)] corresponding to the melting of the majority of the particles. Beyond the third cycle, the DSC curve consistently shows a broad melting peak at $442 \mathrm{~K}$ [Fig. 3(c)] with an occasional peak at $389 \mathrm{~K}$ [Fig. 3(d)]. No other melting peak could be observed. Considering the as-cast peak of $545 \mathrm{~K}$, the observed melting point of $442 \mathrm{~K}$ represents a depression of $103 \mathrm{~K}$. We also note that, although the majority of the particles melted near this temperature, the breadth of the peak and the occasional observation of the small peak at $389 \mathrm{~K}$ indicate the existence of a spectrum in the depressed melting of nanoparticles of $\mathrm{Bi}(\sim 50 \mathrm{~K})$. In contrast, the solidification always occurs with a relatively sharper peak at $367 \mathrm{~K}$ for all the cases (Fig. 3). A quantitative evaluation of the solidification exotherm of the $\mathrm{Bi}$ particles melted just after the peak at $442 \mathrm{~K}$ and after the sample heated up to $570 \mathrm{~K}$ indicates that $80 \%$ of the $\mathrm{Bi}$ particles have already been melted at the end of the depressed melting peak. In situ melting experiments inside the electron micro-

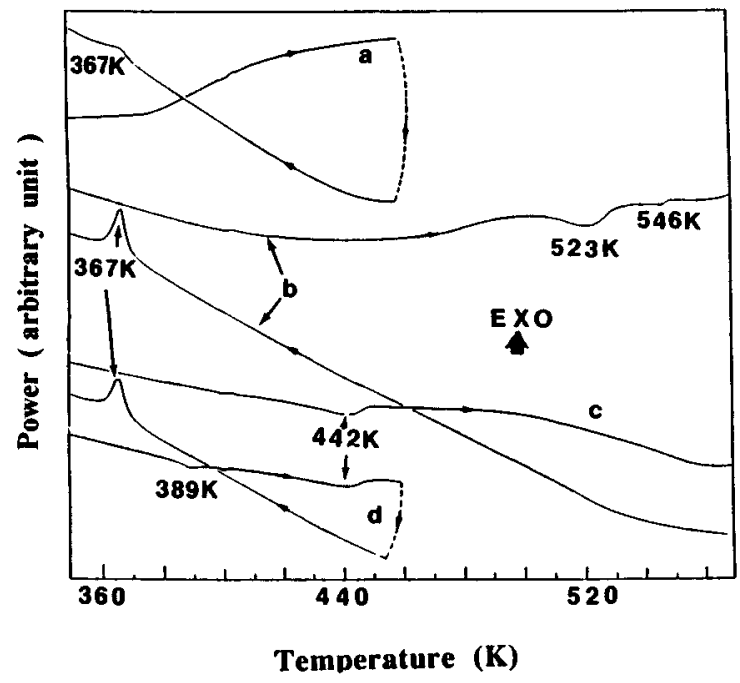

FIG. 3. DSC thermograms revealing the melting and solidification behavior of the nanometric Bi particles. (a) Thermogram of as-spun sample cycled up to a temperature of $460 \mathrm{~K}$. (b) Same as above but cycled up to $580 \mathrm{~K}$. (c) Thermogram of the third cycle of a sample. In each cycle the sample is heated up to $580 \mathrm{~K}$ and cooled to room temperature. Note the depressed melting of the sample. (d) DSC trace of the same sample as "c" ". The cycle is interrupted after the depressed melting peak and cooled. scope using the dark field technique of imaging confirmed the melting point depression of $\mathrm{Bi}$ particles. However, these experiments suggest that the depression shown by the particles are statistical in nature and the same particle often shows different behavior in different cycles.

The formation of the multiple domained nanometric particles during constrained solidification is a new observation which requires an explanation. Multiply twinned particles were observed earlier in nanoparticles obtained by the condensation of vapor. ${ }^{6} \mathrm{We}$ argue that the occurrence of crystallographic variants is related to the requirement of preserving the symmetry of the initial liquid cavity without the loss of continuity at the interface. Considering the diffusion distance, ${ }^{7}$ the shape of the nanosized liquid cavity can be approximated to the equilibrium shape, primarily due to the very short equilibration time that is needed. Therefore, the number of variants needed during solidification for preserving the cavity shape is given by the order of the intersection group of the matrix and the dispersoid. ${ }^{8}$ For the glassy matrix it is infinity. The actual number, however, will be dictated by the heterogeneous nucleation kinetics in the constrained liquid which will promote these variants. It is clear that the number increases during recycling and this aspect needs further study.

In order to understand the observation on melting we have calculated the free-energy difference $(\Delta G)$ between the liquid and solid at the depressed melting temperature from the knowledge of the specific heat of undercooled melt ${ }^{9}$ and using the expression $\Delta G=\Delta S_{v} \Delta T-\int \Delta C p d t$ $-T \int(\Delta C p / T) d t$. The entropy of freezing $\Delta S_{v}$ for $\mathrm{Bi}$ is $0.93 \times 10^{6} \mathrm{~J} \mathrm{~m}^{-3}$. The energy difference needed for the depression of the melting point from the equilibrium value to the temperature range of $389-440 \mathrm{~K}$ is estimated to be 0.7 $\times 10^{8}-0.9 \times 10^{8} \mathrm{~J} \mathrm{~m}^{-3}$. The Bi particle expands when it solidifies. This generates a compressive pressure over the $\mathrm{Bi}$ particles. The volume free energy due to this strain is estimated to be $0.05 \times 10^{8} \mathrm{~J} \mathrm{~m}^{-3}$. ${ }^{10}$ This is negligible compared to the energy required for the melting at $442 \mathrm{~K}$.

In order to rationalize the melting behavior, a number of effects have been considered. The size effect has been calculated using the model of Buffat and Borel. ${ }^{11}$ It is observed that the size of the free particle should be below $2 \mathrm{~nm}$ to expect a depression of melting observed in the present experiments. The minimum size of the particle experimentally observed is $5 \mathrm{~nm}$. In a free state this will yield a melting point of $490 \mathrm{~K}$. The effect of the constraining surfaces in the embedded case is to increase the melting point in comparison to the free state and the magnitude depends upon the contact angle of the nucleating liquid. ${ }^{12,13}$ Thus the size effect cannot explain the observed behavior.

In an alloy, the reduction of size can also lead to enhanced solubility. However, since Bi has repulsive interactions with all the matrix atoms ( $\mathrm{Al}, \mathrm{Fe}$, and $\mathrm{Si})$, the surface energy difference for glassy and crystalline matrices will not be very different. We are successful in crystallizing the matrix by rapid heating without a significant change in the size of the dispersed Bi particles. The DSC melting experiments using these samples do not exhibit any depression of $\mathrm{Bi}$ melting point. In case the solubility is responsible for melt- 
ing point depression, we should have observed some amount of depression in this case as well.

An alternative possible explanation of this early melting behavior is the presence of a metastable form of $\mathrm{Bi}^{14}$ At a very high undercooled level $(\Delta T=220 \mathrm{~K})$ a metastable form of $\mathrm{Bi}$ has been observed. ${ }^{15}$ In the present case, careful diffraction studies using the $\mathrm{x}$-ray and electron as well as high resolution electron microscopy did not reveal any metastable phase in any samples including the ones which showed depression of melting of $80 \%$ of particles. Our experimental observation thus rules out the possibility of the origin of the depressed melting peak due to the presence of metastable $\mathrm{Bi}$.

Fecht has already proposed a model for the defect mediated depression of melting point. ${ }^{16}$ Attempts to explain the presently observed depression of melting point in terms of vacancies and dislocations have yielded an unrealistically high defect concentration. Analysis of our various results clearly suggest that the appearance of the domain boundaries play an important role in the melting point depression. However the exact mechanism and quantitative confirmation is required in the future to understand the observed phenomenon.

To conclude, we have reported the formation of nanocomposites of $\mathrm{Bi}$ particles in a metallic glass matrix and have shown that under a constrained solidification condition, they yield particles with multiple domains. We also report an un- usually large depression of the bulk melting points of the $\mathrm{Bi}$ particles which cannot be explained by the size effect and is clearly related to the phenomenon of the formation of crystallographically related multiple domains.

The work is supported by grants from DAE and DST, Government of India. Additional support came from AOARD under Contract No. F49620-95-1-0105.

${ }^{1}$ R. Goswami and K. Chattopadhyay Acta Metall. Mater. 42, 383 (1994).

${ }^{2}$ R. Nagrajan and K. Chattopadhyay, Acta Metall. Mater. 42, 947 (1994).

${ }^{3}$ Binary Alloy Phase Diagram, edited by T. B. Massalski (ASM, Metals Park, OH 1982).

${ }^{4}$ A. Inoue, M. Yamamoto, H. M. Kimura, and T. Masumoto, J. Mater. Sci. Lett. 6, 194 (1987).

${ }^{5}$ A. K. Nissen, F. R. deBoer, R. Boom, P. F. de Chatel, W. C. M. Mattena, and A. R. Miedema, CALPHAD 7, 51 (1983).

${ }^{6}$ S. Ino, J. Phys. Soc. Jpn. 27, 941 (1969).

${ }^{7}$ W. P. Ellis and N. H. Nachtrieb, J. Appl. Phys. 21, 804 (1950).

${ }^{8}$ J. W. Cahn and G. Kalonji, in Solid-Solid Phase Transformation, edited by H. I. Aaronson, D. E. Laughlin, R. F. Sekerka, and C. M. Wayman (TMS, Warrendale, 1983), p. 3.

${ }^{9}$ J. H. Perepezko and S. J. Paik, J. Non-Cryst. Solids 61, 113 (1994).

${ }^{10}$ D. R. Uhlman, J. Non-Cryst. Solids 41, 347 (1980).

${ }^{11} \mathrm{Ph}$. Buffat and J.-P. Borel, Phys. Rev. A 13, 2287 (1976).

${ }^{12}$ R. Goswami and K. Chattopadhyay, Philos. Mag. Lett. 68, 215 (1993).

${ }^{13}$ H. Saka, Y. Nishikawa, and T. Imura, Philos. Mag. A 57, 895 (1988).

${ }^{14}$ C. J. Hofman, J. Phys. Chem. Solids 36, 1249 (1975).

${ }^{15}$ J. H. Perepezko, in Second International Conference on Rapid Solidification Processing: Principle and Processing, edited by R. Mehrabian, B. H. Kear, and M. Cohen (Claitor's, Baton Rouge, 1980), p. 56.

${ }^{16}$ H. Fecht, Nature 356, 133 (1992). 